\title{
Chemocommunication among prey and predator species
}

\author{
ROBERT COCKE and DEL D. THIESSEN \\ University of Texas, Austin, Texas
}

\begin{abstract}
Extensive chemocommunication occurs between individuals of different species. We examined the interaction between Mongolian gerbils (Meriones unguiculatus) and between domestic cats (Felis domestica). Experiments indicated that stressed gerbils produce blood odors that stimulate physiological arousal and cause conspecifics to avoid areas contaminated with these odors. Domestic cats preferred these same odors and differentially consumed food contaminated with these odors. Both reactions are ecologically important in the interaction between prey and predator.
\end{abstract}

Chemical signals are often used by prey and predator species to facilitate avoidance or orientation. Injured individuals of several species of insects, reptiles, and mammals produce alarm odors (Schreckstoff) that cause arousal, freezing, dispersal, or mobbing behaviors in conspecifics (Muller-Schwarze, 1979; Pfeiffer, 1962). For example, the alarm substance in ants causes aggregation, dispersal, or defensive attack, depending on the status of the recipient in the colony (Wilson, 1985). Rodent alarm odors evoke freezing or escape responses, depending on the environment in which they are presented (Tarpy, 1981). The reactions appear to be adaptations to potential or actual predatory attack. Predator species, on the other hand, may use these odors to localize prey animals and to assess their defensive capabilities. The least weasel (Mustela nivalis) tracks deer mice (Peromyscus bairoli) by olfactory cues (Cushing, 1984), and garter snakes (Thamnophis sirtalic) innately respond to and orient toward odors of species upon which they prey (Burghardt, 1970). Finally, prey species may have the capability of sensing and reacting adaptively to odors produced by predators. When the odor of fox feces is presented to rodents, a fear response is elicited (Cattarelli \& Chanel, 1979). The snowshoe hare (Lepus americanus) displays a similar reaction to the odors of mustilid predators (Sullivan, Nordstrom, \& Sullivan, 1985a, 1985b). Thus, it appears that a complex chemosensory interaction exists between prey and predator species.

The purpose of these experiments was to demonstrate that odors from stressed Mongolian gerbils (Meriones unguiculatus) cause conspecific physiological arousal. In several species, when the odor of an injured animal is presented to a conspecific, physiological arousal results. When the alarm substance of the honeybee (Apis mellifera) is introduced into the colony, the metabolic rate of the colony rises, suggesting an increase in arousal (Southwick

This work was supported by NIMH Grant MH 14076-19 awarded to D. D. Thiessen. Special thanks to Lloyd Berg for his laboratory contributions. The authors' mailing address is: Department of Psychology, University of Texas at Austin, Mezes Hall 330, Austin, TX 78712-7789.
\& Moritz, 1985). In king snakes (Lampropeltus getulus), the alarm odor of a stressed animal arouses nonstressed conspecifics (Brisbin, 1968). We speculate that rodent alarm odors are attractive to animals that prey upon rodents and may be used for orientation during foraging. We therefore suggest that stressed or injured rodents avoid each other in order to reduce the hazards associated with predator orientation toward prey stress odors.

\section{EXPERIMENT 1}

\section{Method}

Fifty-two male Meriones unguiculatus, approximately 120 days of age, housed individually at $23^{\circ} \mathrm{C}$ ambient temperature and $40 \%$ relative humidity under a 12/12 light/dark cycle, were used as odor donors. Twenty-six of these were used to generate stress odors (SOs). We adapted the procedure of Mackay-Sims and Laing (1981) for the production of rodent alarm odors. The animals were removed from their home cages, individually placed in a foot-shock apparatus (Lehigh Valley Model No. 4615A), and exposed to two sessions of 30-sec scrambled electrical shock $(2.5 \mathrm{~mA}, 600 \mathrm{~V})$ separated by a 2 -min rest interval. Fifteen minutes after the second shock session the animals were removed from the apparatus and sacrificed by cervical sectioning; their blood was collected in a heparinized watch glass. The other 26 animals donated control odors (COs). CO blood was collected from individual animals immediately after they were removed from their home cages; otherwise the procedure was identical to that for the stressed animals. All tests were conducted during the light half of the light/dark cycle.

Because of its robustness and ease of measurement, increase in body temperature was used as an index of physiological arousal (Schmidt-Nielsen, 1979). Body temperature was measured in 9 test animals with surgically implanted biotelemetry radio transmitters (Mini-mitter, Model M) according to the procedure described by Thiessen and Kittrell (1980). Two weeks after surgery, individuals were placed in a Plexiglas activity apparatus that measured $40 \times$ $34 \times 25 \mathrm{~cm}$ (Animex, Model Type O, Farad Electronics) and was enclosed in an unlighted and soundproof cabinet. A filtered airstream (1.2 liters $/ \mathrm{min}$ ) was directed through the apparatus from odor donor jars on the outside of the chamber. Either SO or CO could be directed into the apparatus. The ambient temperature $\left(23^{\circ} \mathrm{C}\right)$ of the chamber was monitored continually and the animal's body temperature and activity in the Animex apparatus were recorded on a Coulbourn printer (Model R22-10). Ten successive intersignal intervals from the transmitters were summed and averaged by the Coulbourn instrument. This procedure generated a fourth significant digit, which allowed for accurate measurement of relatively small tem- 
perature changes $\left(<.05^{\circ} \mathrm{C}\right)$. Locomotion was scored as the number of times the animal passed over six electromagnetic sensors built into the floor of the Animex chamber. After the animal had been habituated to the apparatus for $\mathbf{4 5} \mathrm{min}$, the blood odor from either the $\mathrm{SO}$ or $\mathrm{CO}$ condition was introduced into the airstream of the chamber for $30 \mathrm{~min}$. Each animal was exposed to both odors on alternate days in a counterbalanced sequence.

\section{Results}

The average increase in body temperature, shown in Figure 1, was significantly greater among animals exposed to SO than among those exposed to $\mathrm{CO}(t(8)=$ $4.18, p<.02$ ). There was no significant difference in locomotor activity, although there was a trend toward lower activity during SO presentations, and there were no covariations between body temperature, locomotion, and ambient temperature. Thus, the primary effect of exposure to the blood odors of stressed animals was an average increase of $.38^{\circ} \mathrm{C}$ in body temperature. SOs therefore appear to physiologically arouse conspecifics.

\section{EXPERIMENT 2}

\section{Method}

Experiment 2 was an attempt to demonstrate that presentation of blood-borne SOs not only results in physiological arousal but also causes avoidance in conspecifics, a finding similar to those reported by Mackay-Sims and Laing (1981) and Stevens and Gerzog-Thomas (1977). Animals were housed and tested as in Experiment 1. We employed a multi-alley Lashley III maze, which measured $42 \times$ $17 \times 96 \mathrm{~cm}$ overall and consisted of four $96 \times 17 \times 18.5 \mathrm{~cm}$ runways involving three choice points. The maze was covered with clear $1 / 4$-in. Plexiglas and the floor was covered with butcher paper. Air was pulled from the start box and through the apparatus at approximately $.75 \mathrm{liter} / \mathrm{min}$. Approximately $.25 \mathrm{ml}$ of blood from either an SO or a $\mathrm{CO}$ donor was swabbed on the paper flooring midway through the maze immediately before each trial; thus, the animals would progress through half of the maze before encountering the stimulus or its airborne odors. Twenty male gerbils with no prior experience in the maze were placed individually in the start box and admitted to the maze via a guillotine door for $5 \mathrm{~min}$ of free exploration. Ten individuals encountered the SO and 10 encountered the $\mathrm{CO}$. The running of the two conditions was alter-

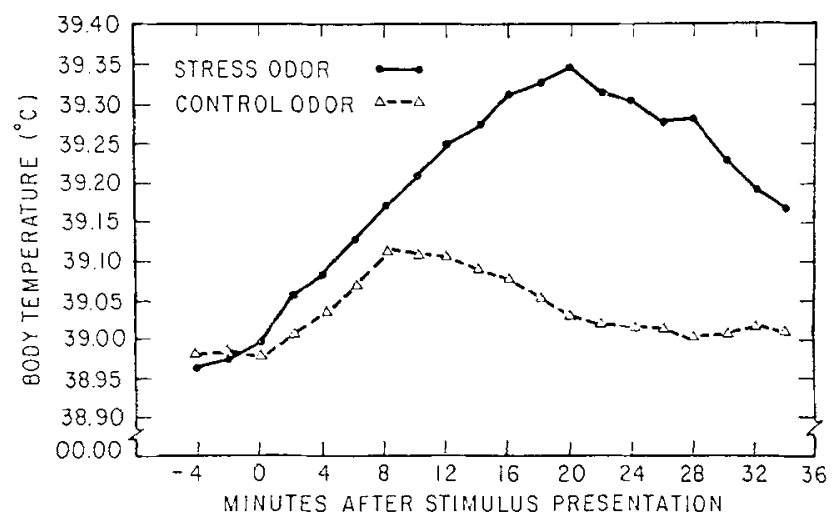

Figure 1. Body temperature change in response to blood odors from stressed or nonstressed Meriones unguiculatus. nated, and the test animals were randomly assigned to the SO and $\mathrm{CO}$ encounters. Between trials, the walls of the maze were washed with $50 \%$ ethanol and the paper flooring was changed. Videotapes of each trial were analyzed for the amount of time that animals spent upwind or downwind from the odor sources and for the frequency of crossings over the blood spots in the alleyway.

\section{Results}

The average time spent downwind of the odor source was $49 \mathrm{sec}$ and $139 \mathrm{sec}$ for the animals in the $\mathrm{SO}$ and $\mathrm{CO}$ conditions, respectively $(t(18)=6.74, p<.001)$, and the average number of times that animals in the SO and CO conditions crossed the blood spot was .3 and 1.9 , respectively $\left(\chi^{2}(1)=10.2, p<.01\right)$. Thus, in terms of both time spent downstream of the odor source and probability of crossing over the odor source, animals encountering the blood from stressed animals showed more avoidance. In addition, 2 subjects that encountered the SO immediately developed tonic-clonic seizures. Apparently, odors from the blood of stressed gerbils physiologically arouse recipients (as indicated by elevations in body temperature) and also evoke evasive behaviors.

\section{EXPERIMENT 3}

\section{Method}

Our next question was whether the odors that stimulated arousal and avoidance in prey animals also were attractive to rodent predators. In pilot investigations, we found that foxes (Vulpes), ferrets (Mustela putorius furo), and domestic cats (Felis domestica) sought out blood odors from stressed gerbils. In Experiment 3, therefore, we attempted to verify this differential orientation by testing the food preferences of domestic cats exposed to SOs or COs in their food. Twenty-three male and female cats were tested at a local cattery for food preferences. The exact ages of the cats were unknown, but they ranged from adolescence to maturity. Both sexes were represented in approximately equal numbers. The cats were individually housed in stainless steel cages $(60 \times 38 \times 40 \mathrm{~cm})$ exposed to natural lighting and maintained at approximately $23^{\circ} \mathrm{C}$. Thirty minutes prior to their normal feeding time $(1600 \mathrm{~h})$, a twocompartment bowl with $20 \mathrm{~g}$ of dry Purina cat chow in each side was placed in each subject's home cage. One compartment of the bowl contained three additional food pellets saturated with the blood from SO animals and the other compartment contained three additional food pellets saturated with the blood from $\mathrm{CO}$ animals. The food bowl remained in the cage for $5 \mathrm{~min}$, with the positions of the SO and CO compartments rotated every $90 \mathrm{sec}$. The initial food preference and the amount of food eaten for each compartment were recorded.

\section{Results}

The majority of cats initially oriented toward and selected the food from the compartment containing the SO (17 vs. $\left.6, \chi^{2}(1)=4.34, p<.05\right)$, and the greater amount of food was eaten from this compartment $(\bar{X}=$ $5.56 \mathrm{~g}$ vs. $1.52 \mathrm{~g}, t(22)=3.30, p<.01)$. It appeared that the cats were initially attracted to the SO and then tended to persist in eating on that side even after the pellets saturated with SO were eaten. We view these findings as evidence that predators appear to be attracted to the odors 
from the blood of stressed rodents and may accept these odors as part of their food source.

\section{DISCUSSION}

Our findings support the notion that prey and predator species react differently to odors of stressed prey animals. Our initial (unpublished) findings indicated that wholebody odors of stressed gerbils were sufficient to cause these reactions, but that the reactions were intensified when blood was used as the stimulus. As the present experiments show, gerbils are aroused by blood odors from stressed conspecifics and avoid sources of these odors. Cats, on the other hand, seek out these odors, and prefer food saturated with blood containing these odors. As far as we are aware, this is the first study to demonstrate both that prey animals avoid conspecific odors associated with stress and injury and that predators orient toward and prefer these same odors. These results suggest that individuals of prey species avoid odors from stressed conspecifics in order to avoid predators that are attracted to these odors. Predators, on the other hand, may utilize these odors for orientation toward prey animals and for choosing individuals who may be injured and partially disabled. There is also evidence that rodents and other prey species avoid areas odorized by some predators (Cattarelli \& Chanel, 1979; Griffith, 1920; Stoddart, 1979; Sullivan et al., 1985a, 1985b), suggesting that there is three-way chemocommunication taking place among rodents and their predators. Individuals of prey species avoid conspecifics who are stressed or injured and also avoid odors of potential predators; predators orient toward the odors of stressed prey animals. A selective advantage could be attributed to the utilization of these cues in the chemical ecology of both prey and predator. The prey is apparently reducing the probability of predatory attack. At the same time, the predator may inadvertently contribute to the overall integrity of the prey population by culling injured or traumatized individuals. For example, there is evidence that individuals caught by predators are in poorer physiological and behavioral condition than members of the population as a whole (Gosling \& Petrie, 1981). We are now trying to identify the blood odorants and the extent of chemocommunication among other prey and predator species that interact.

\section{REFERENCES}

BrisBiv, I. L. (1968). Evidence for the use of post anal musk gland as an alarm device in the king snake, Lampropelietis getulus. Herpetologica, 24, 169-170.

BURghaRdT, G. M. (1970). Chemical perception in reptiles. In J. W. Johnson, D. G. Moulton, \& A. Turk (Eds.), Communication by chemical signals (pp. 241-308). New York: Appleton-Century-Crofts.

Cattarelli, M., \& Chanel, J. (1979). Influence of some biologically meaningful odorants on the vigilance states of the rat. Physiology \& Behavior, 23, 831-838.

Cushing, B. S. (1984). A selective preference by least weasels for oestrous versus dioestrous urine of prairie deer mice. Animal Behavior, 32, 4-5.

Gosling, L. M., \& Petrie, M. (1981). The economics of social organization. In C. R. Townsend \& P. Calow (Eds.), Physiological ecology (pp. 315-345). Oxford: Blackwell Scientific Publications.

Griffith, C. R. (1920). The behavior of white rats in the presence of cats. Psychobiology, 2, 19-28.

Mackay-Sims, A., \& LaING, D. G. (1981). Rats' responses to blood and body odors of stressed and non-stressed conspecifics. Physiology \& Behavior, 27, 503-510.

Muller-SChWARZE, D. (1979). Chemical signals in alarm behavior of deer. In D. Muller-Schwarze \& R. M. Silverstein (Eds.), Chemical signals: Vertebrates and aquatic invertebrates (pp. 39-51). New York: Plenum Press.

Pfeiffer, W. (1962). Alarm substances. Experientia, 19, 113-168.

SChmidt-Nielsen, K. (1979). Animal Physiology (2nd ed.). Cambridge: Cambridge University Press.

Southwick, E. E., \& Moritz, R. A. (1985). Metabolic response to alarm pheromone in honeybees (Apis mellifera). Journal of Insect Physiology, 31, 389-392.

Stevens, D. A., \& Gerzog-Thomas, D. A. (1977). Fright reactions in rats to conspecific tissue. Physiology \& Behavior, 18, 47-51.

STODDART, D. M. (1979). Some responses of a free living community of rodents to the odors of predators. In D. Muller-Schwarze \& R. M. Silverstein (Eds.), Chemical signals: Vertebrates and aquatic invertebrates (pp. 1-10). New York: Plenum Press.

Sullivan, T. P., Nordstrom, L. O., \& Sullivan, D. S. (1985a). Use of predator odors as repellents to reduce feeding damage by herbivores: I. Snowshoe hares (Lepus americanus). Joumal of Chemical Ecology, 11, 903-919.

Sullivan, T. P., Nordstrom, L. O., \& Sullivan, D. S. (1985b). Use of predator odors as repellents to reduce feeding damage by herbivores: II. Black-tailed deer (Odocoileus hemionus columbianus). Journal of Chemical Ecology, 11, 921-935.

TARPY, R. (1981). Avoidance. In D. McFarland (Ed.), The Oxford companion to animal behavior. New York: Oxford University Press.

Thiessen, D. D., \& Kittrell, M. W. (1980). The Harderian gland and thermoregulation in the gerbil (Meriones unguiculatus). Physiology \& Behavior, 24, 417-424.

WiLSON, E. O. (1985). The sociogenesis of insect colonies. Science, 228, 1489-1495,

(Manuscript received August 14, 1985; revision accepted for publication December 12, 1985.) 